\title{
Personal Contact through Personal Narratives: Attitudes of Fifth-Grade Children toward Children Who use Augmentative and Alternative Communication
}

\author{
Laura M.D. Smucker ${ }^{1}$, John W. McCarthy ${ }^{2}$, Joann P. Benigno ${ }^{2}$ and Jamie B. Boster ${ }^{2}$ \\ ${ }^{1}$ Meeting St. Early Intervention, Providence, RI, United States \\ ${ }^{2}$ Communication Sciences and Disorders, Ohio University, Athens, OH, United States \\ Email: mccarthj@ohio.edu
}

\begin{abstract}
There is a lack of interventions to understand and change attitudes of school-age children toward peers with severe speech and physical disabilities. The effect of reading a first-person narrative on the attitudes of 66 fifth-grade children toward individuals who use augmentative and alternative communication (AAC) was investigated using a quasi-experimental design. Children were randomly assigned to either an experimental narrative condition $(\mathrm{n}=37)$ or a control non-fiction, nondisability condition $(\mathrm{n}=29)$. Children's prior experience with individuals with disabilities and their biological sex had significant effects, with girls and those with previous experience having more positive attitudes than boys and those with no previous experience. Pre/post differences highlighted the potentially reactive nature of attitude testing. Reading the narrative did not lead to significant differences between groups in mean attitudes, but qualitative analyses revealed that the narrative led to a more comprehensive view of people with severe communication challenges and highlighting the misconceptions that many school-age children might have toward individuals with severe communication challenges.
\end{abstract}

Keywords: Attitudes, augmentative and alternative communication (AAC), children, personal narrative.

\section{Introduction}

Understanding how to have successful inclusive educational environments can be informed by considering inclusion of children with multiple, significant disabilities. Children with developmental disabilities such as cerebral palsy, autism, and intellectual disabilities may have speech impairments so severe that their natural speech is not adequate to meet their daily communication needs. These children can benefit from augmentative and alternative communication (AAC) strategies including photographs, line drawings, signs, alphabet boards, gestures, and high-tech communication systems with synthesized speech output. Despite changes in school placements and inclusionary practices, children with disabilities still face significant challenges in gaining acceptance by their peers [1]. The complex nature of disabilities for individuals requiring AAC may impact their inclusion, in that they are either not regularly included or are placed in specialized classrooms serving only children with disabilities $[2,3]$. Children, especially those with intellectual disabilities, still experience negative attitudes in schools; even when schools have inclusive policies [4].

Just being physically present in classrooms is not enough. Children with disabilities need support and accommodations and children without disabilities need accurate information and guidance to be successful partners and to avoid perpetuating stereotypes leading to reduced expectations and marginalization of children seen as "different." Efforts have been made to impact the attitudes of children towards children across disability types with short training programs. These trainings may include multiple components. For example, one intervention specifically explored the effects of a shortterm disability training program with adolescent boys that included guest speakers from Paralympics and Special Olympics, documentaries about people with disabilities, disability simulation activities and presentation of information about disabilities [5]. Results of the training program indicated improved attitude scores that were maintained even after a one-month follow-up [5]. These results suggest that a range of training methods may be implemented to achieve changes in attitudes related to children with 
disabilities. A systematic review of 35 studies exploring the association between children's contact with people with disabilities and their attitudes towards disability itself indicated that more contact resulted in more positive attitudes [6].

Although direct contact is a preferred method to change attitudes [7], finding other avenues short in duration and through more indirect methods [8] could represent an important first step in 'opening the door' for children with disabilities to gain recognition and positive acceptance from their school-aged peers. Results of focus groups with children who used AAC indicated that children themselves felt their AAC systems were "uncool" or "boring" and that they negatively impacted their self-image [9]. It is possible that same-age peers also view AAC in a similar way and may retain negative attitudes towards children who use such systems. A research review of students' attitudes towards peers with disabilities concluded that future direction in this area should include interventions to change attitudes that include different perspectives as well as increasing knowledge about disabilities [10]. There is limited research on such short-term, high-impact interventions for changing the attitudes of children without disabilities toward children requiring AAC [11]. Prior research has found that providing children with factional information about disabilities was not enough to promote changes in the attitudes of 95 children across grades 2, 4, and 6 in a suburban elementary school [12]. Research also assessed the impact of providing information in addition to a role-playing activity where children used a communication board instead of talking to play a card game [12]. The results of this iteration suggested that role-playing activities led to larger changes in attitudes when compared to providing information alone [12].

Unfortunately, it is not always possible to arrange ideal contact on a cooperative scale uniformly in all schools. McCarthy, Donofrio-Horwitz, and Smucker [13] suggested that using personal narratives is a potential solution. Narratives provide an indirect way of meeting another individual and provide accurate information and insight into the life experiences of others [14]. Using narratives may also increase perceived similarity between individuals who do and do not use AAC. McCarthy and colleagues found that reading a short narrative written by an individual using AAC positively impacted attitudes of undergraduate business students toward that person and had a positive impact on future hiring behavior [13]. The idea of contact through a means beyond face to face has been called "extended contact" in the adult literature [15] and focuses on the idea of highlighting positive interactions between separate groups (such as those who might experience prejudice and those who do not). Cameron and Rutland explored "extended contact" and applied the concept to children [16]. The authors found that children aged 5-9 who read accounts of friendship between children with and without disabilities in small groups with an experimenter over a six-week period, had more positive views toward people with disabilities than those who did not complete the extended contact. The distinction between learning disability and physical disability did not appear to have an impact on the results. Research from Cameron and colleagues suggested that attitude changing contact need not be face to face or even protracted [17]. The authors reported that merely imagining positive contact with a child with a physical disability for three minutes reduced bias in children aged 5-10. It was only children aged 5-6 who reported more behaviors associated with friendship in response to a hypothetical scenario than children who did not imagine contact. The authors suggested that direct contact could override indirect contact and since older children were more likely to have direct contact, it was more difficult to influence friendship behaviors. It seems possible that targeting older children with more limited previous contact with children with disabilities in an indirect contact situation could help to elucidate a potential age and experience relationship. It is also possible that asking more qualitative questions regarding friendship could aid in understanding the perspectives of older children toward a child with a severe physical and communication disability.

Lee and Rodda [18] asserted that negative attitudes towards individuals with disabilities might result from inaccurate information about disabilities. In addition, lack of experience with individuals with disabilities may nurture negative attitudes and create anxiety in others who encounter them. In a metaanalysis related to attitude change, Shaver and colleagues [19] found that relative to providing basic information, persuasive messages were more effective at changing attitudes. Both Shaver [19] and Lee and Rodda [18] reported the combined effect of accurate information and contact results on the most positive attitude modification. This effect is created by learning new information that replaces old, inaccurate beliefs. Then, exposure to someone with a disability reinforces and verifies the accuracy of the information presented, but not all forms of contact are equal. Cooperative situations with support from authority figures such as teachers appear to be the most effective [1]. 


\subsection{The Present Study}

The current study aimed to integrate and extend previous findings of the effectiveness of a single personal narrative reading on attitudes toward individuals who use $\mathrm{AAC}$, the positive findings of extended contact with children in longer and short, imagined contexts. The purpose of the present study was to assess children's attitudes toward individuals who use AAC and examine whether reading a personal narrative influenced shifts in their attitudes. The research questions were: (a) What are the baseline attitudes of school-aged children toward individuals who use AAC? (b) What is the effect of reading a first-person narrative on children's attitudes toward individuals who use AAC? (c) What are the perspectives on friendship and the future of school-aged children toward the author of the experimental narrative? It was predicted that the baseline measurement of attitudes would be neutral, not negative, based on previous studies using the Assessment of Attitudes Toward Augmentative and Alternative Communication (AATAAC) $[4,20]$. It was hypothesized that reading a first-person narrative would have a positive impact on children's attitudes. Also, given the empirical precedence in the literature, biological sex differences were anticipated.

\section{$2 \quad$ Method}

\subsection{Experimental Design}

A quasi-experimental mixed factorial design (3 between-subject variables; 1 within-subject variable) was used: 2 (group: experimental vs. control) $\times 2$ (sex: female vs. male) $\times 2$ (experience: yes vs. no) $\mathrm{x} 2$ (time: sessions). The independent variable was the condition of the experimental narrative or the control reading, and the dependent variable was the aggregate score on the AATAAC, a self-report measurement of attitudes. Additionally, during session two, both groups answered three open-ended, qualitative questions after completing the attitude assessment. The qualitative responses of the experimental group were coded and analyzed for themes.

\subsection{Participants}

Participants in the study consisted of six, fifth-grade classrooms from two elementary schools in southeastern Ohio. There were three classrooms in the control group $(n=29 ; 13$ females $)$ and three classrooms in the experimental group ( $n=37 ; 23$ females). Based on teacher report from all classrooms, each child could read at or above grade level. Students $(n=16$ experimental, 13 control) who reported that they either had a friend who had a disability or that they had talked or played with someone with a disability during the past week, at any time during the three sessions, were considered as having previous experience with individuals with disabilities.

\subsection{Materials}

The narrative read to students in the experimental condition was Kathrin Talks with Her Eyes [21]. The narrative is in an illustrated children's book portraying, in first-person voice, the life of a young girl who uses AAC and her experiences. The story read to the students in the control condition was If You Decide to Go to the Moon [22], an illustrated nonfiction children's book. The experimental story had a reading level of 4.4 as measured by the Flesch-Kincaid Grade Level Measurement on Microsoft Word and consisted of 1,532 words, and 18 illustrations. The control story was matched to reading level, number of words, and number of illustrations. The stories were read from a script and corresponding pictures were shown directly from the books.

\subsection{Measures}

The Assessment of Attitudes Toward Augmentative/Alternative Communication (AATAAC) was used to measure attitudes [20]. The AATAAC is used for measuring attitudes of school-aged children in the first through fifth grades. The AATAAC has acceptable internal consistency (.95) and test-retest reliability after one week $(\mathrm{a}=.01$ and $r=.87)$. 


\subsection{Procedures}

IRB approval and consent of parents and students was obtained first. During the first session, the researcher provided a brief, standardized introduction to AAC. After the description of AAC, the researcher passed out a demographic questionnaire. Each child was given a $5 " \times 7$ " color copy of an illustration of Kathrin from the experimental reading to refer to as an example of a child who uses AAC. The students were told Kathrin is a child who uses AAC and to think of people 'like Kathrin' while filling out the AATAAC. Students then completed the assessment. The second session took place exactly one week after the first. The session began with the researcher reading the story to each group. The experimental group heard Kathrin Talks with Her Eyes [21] and the control group heard If You Decide to Go to the Moon [22]. To control for children not reading at grade level, the stories were read aloud by the researcher. After reading the story, the researcher read the standardized introduction to $\mathrm{AAC}$ as well as the instructions and sample questions for the AATAAC. The illustration of Kathrin was also provided and the students completed the AATAAC for the second time. Students also answered three questions about the story that was read, to gain insight into their perspectives about AAC and individuals who use AAC. The questions asked were: what do you think would be good about being friends with someone like Kathrin; what do you think would be challenging about being friends with someone like Kathrin; what do you think someone like Kathrin will be when she grows up; why do you think that?

\subsection{Data Analysis}

Scores for the AATAAC were calculated and a mean score was determined for each participant as described by Beck and colleagues [20]. Mean scores closer to 5 were considered to reflect more positive attitudes; scores closer to 1 were considered to reflect more negative attitudes. A mixed factorial ANOVA was used to analyze interactions and main effects among variables. The qualitative responses of the experimental group were transcribed and coded for themes using procedures outlined by Vaughn, Schumm, and Sinagub [23]. Individual responses were transcribed and broken down into thought units. A thought unit is the smallest unit that can stand alone and maintain its original meaning. Thought units were then coded and analyzed for themes.

\subsection{Reliability}

Four sessions were randomly selected and procedural reliability was $100 \%$. For the qualitative portion of the study, an independent coder established the reliability of themes by recoding $25 \%$ of the data. Forty thought units were re-coded for themes with 93\% (40/43) agreement. Disagreements were resolved through discussion.

\section{$3 \quad$ Results}

\subsection{Baseline Attitude Scores}

The mean baseline AATAAC score for girls was $3.81(\mathrm{SD}=.48)$ and $3.45(\mathrm{SD}=.53)$ for boys. Mean baseline AATAAC score for individuals with experience was $3.93(\mathrm{SD}=.39)$ and mean AATAAC score for individuals without experience was $3.45(\mathrm{SD}=.53)$.

\subsection{Effect of Reading the Narrative}

The mixed factorial ANOVA revealed a main effect for the between-subjects factors of experience $(F[1$, $58]=13.835, p=<.001)$ and $\operatorname{sex}(F[1,58]=4.90, p=.03)$. AATAAC scores were higher for children with experience with disabilities than those without experience. Girls had higher AATAAC scores than boys. Group was not significant $(F[1,58]=.81, p=.37)$. The within-subject factor of time $(F[1,58]=$ $4.94, p=.03)$ was significant. Scores on the AATAAC were higher at Time 1 than Time 2. There were no significant interactions between any of the factors. Descriptive statistics are presented in Table 1. 
Table 1. Mean attitude scores for participants across sessions

\begin{tabular}{lll}
\hline & Session One Mean (SD) & Session Two Mean (SD) \\
\hline Experimental Group & $3.78(.47)$ & $3.57(.66)$ \\
Control Group & $3.52(.57)$ & $3.49(.68)$ \\
Male & $3.45(.53)$ & $3.27(.71)$ \\
Female & $3.81(.48)$ & $3.72(.59)$ \\
Experience & $3.93(.39)$ & $3.82(.52)$ \\
No Experience & $3.45(.53)$ & $3.32(.71)$ \\
Time & $3.66(.48)$ & $3.54(.68)$ \\
\hline
\end{tabular}

\subsection{Qualitative Analysis}

A summary of the themes that emerged from the qualitative analysis can be found in Table 2.

Table 2. Themes, subthemes and example responses from 5th-grade children's responses to reading, "Kathrin Talks with her Eyes"

\begin{tabular}{|c|c|c|}
\hline Theme (\# of thought units) & Subtheme (\# of thought units) & Examples \\
\hline \multirow[t]{3}{*}{ Kathrin's physical status (18) } & Physical limitation (8) & "They can't really move around a lot." \\
\hline & Physical ability (7) & $\begin{array}{l}\text { "Because people who have AAC can do } \\
\text { everything a person without AAC can do." }\end{array}$ \\
\hline & Play difficulty (3) & $\begin{array}{l}\text { "You don't get to play as many things like } \\
\text { other kids." }\end{array}$ \\
\hline \multirow[t]{2}{*}{ Communication (36) } & $\begin{array}{l}\text { Difficulty for communication } \\
\text { partner }(25)\end{array}$ & "Trying to understand her sometimes." \\
\hline & Difficulty for Kathrin (1) & "They can't speak." \\
\hline \multirow[t]{3}{*}{$\begin{array}{l}\text { Personal Characteristics of } \\
\text { Kathrin (35) }\end{array}$} & Good person (19) & $\begin{array}{l}\text { "Kathrin will be a wonderful person even } \\
\text { though I haven't met her she seems really } \\
\text { nice." }\end{array}$ \\
\hline & Smart (7) & "They might be a genius when they grow up." \\
\hline & Empathetic (9) & $\begin{array}{l}\text { "She might want other children to be treated } \\
\text { fairly." }\end{array}$ \\
\hline \multirow[t]{7}{*}{ Occupations for Kathrin (41) } & Teacher $(5)$ & "A very good person like a teacher." \\
\hline & AAC teacher (13) & "A teacher who teaches AAC children." \\
\hline & Sign language teacher (3) & $\begin{array}{l}\text { "Well since she has a disability she could } \\
\text { teach sign language to be a teacher." }\end{array}$ \\
\hline & Special education teacher $(2)$ & $\begin{array}{l}\text { "I think they would be a teacher in a } \\
\text { handicap school." }\end{array}$ \\
\hline & Doctor (2) & "A doctor who helps people speak." \\
\hline & Other (artist, parent, etc. (10) & "I think they could be a good story writer." \\
\hline & Unemployed (3) & $\begin{array}{l}\text { "She probably won't have a job. Because the } \\
\text { owner would not want them." }\end{array}$ \\
\hline \multirow{3}{*}{$\begin{array}{l}\text { Benefits for peers interacting } \\
\text { with someone like Kathrin (14) }\end{array}$} & Positive/good experience (7) & "I would have a fun experience." \\
\hline & $\begin{array}{l}\text { Play }(4) \\
\text { Difference does not matter }(3)\end{array}$ & $\begin{array}{l}\text { "You can play lots of games with her." } \\
\text { "I think Kathrin would be a great friend } \\
\text { because it doesn't matter if she uses AAC." }\end{array}$ \\
\hline & Educational experience (5) & "You could learn about AAC." \\
\hline \multirow{2}{*}{$\begin{array}{l}\text { Benefits for someone like } \\
\text { Kathrin in interacting with } \\
\text { others (19) }\end{array}$} & Lack of friends (4) & $\begin{array}{l}\text { "It would be good because they probably } \\
\text { don't have many friends." }\end{array}$ \\
\hline & Make her happy (3) & It would make her happier." \\
\hline
\end{tabular}




\begin{tabular}{|c|c|c|}
\hline Other (12) & General comment (8) & $\begin{array}{l}\text { "My friend Carlean don't get much friends } \\
\text { but me." }\end{array}$ \\
\hline
\end{tabular}

\section{Discussion}

\subsection{Mean Attitude Score Changes}

Contrary to predictions, placement in the experimental group did not result in significantly higher AATAAC scores compared to the control group. Regardless of group, mean AATAAC scores were lower during session two. There are three potential explanations: the content of the narrative, the length of the intervention, and the attitude measure. First, the content of the narrative was not designed specifically to change attitudes. The narrative was informative and talked about a particular child's life. For the narrative to be influential at changing attitudes, it would need to include more elements of persuasion, such as a direct challenge to old attitudes and a story that allows the reader to truly feel 'inthe-shoes' of the narrator [14]. According to Dal Cin and colleagues, another possibility is that narratives can be particularly effective at changing only those attitudes that are very strong and resistant to change [14]. As predicted at baseline measurement, participants in this study did not report having strongly negative attitudes. Therefore, since the participants' attitudes were not very negative at the outset, they were not easily changeable, regardless of the narrative content. In another study of indirect contact, Cameron, Rutland, and Brown [24] instructed participants to imagine positive interaction scenarios. Cameron and colleagues [17] used narratives where both individuals with and without disabilities were always portrayed as positive. Positive contact in this case would ensure a reduction of bias. The current narrative had no controls for the reactions of participants, and it is possible the challenges noted by the author in the narrative served to activate bias rather than overcome it. The second explanation is that the intervention was not long enough to change attitudes. First, students were exposed briefly to AAC through a standardized introduction and the initial exposure to the AATAAC. The intervention that took place during the second session provided a brief, ten-minute, informational story about a girl who uses AAC. Potentially, a longer informational session might have had more of an impact on attitudes and beliefs. Previous work by Cameron and colleagues [17] suggests that brief forms of indirect contact through reading stories about individuals with disabilities over an extended period (6 weeks) can have an impact, although that impact may be limited to younger children (ages 5-9). The length of intervention required for pre-adolescent children similar in age to those in our investigation is less certain. Third, the attitude assessment might have had an impact on the results. The AATAAC measures global attitude change toward 'children who use AAC.' Participants in the study were only exposed to one child who uses AAC and therefore were only exposed to one AAC system. McCarthy and colleagues [13] found that reading a first-person narrative had a positive effect on the attitudes of college students toward an individual using AAC. The study with adults used an attitude measurement with the wording 'this person,' meaning that their attitudes were measured according to their knowledge of only one person (the person they were exposed to). Therefore, it is more likely that the attitudes of children in this study might have changed significantly if their attitudes had been assessed relative to a single person. These findings (the discrepancy between the narrative study with adults and the current study) are analogous to extant attitude studies in AAC with adults versus children. Blockberger and colleagues [25] and Gorenflo and Gorenflo [26] failed to replicate findings of attitude differences in children according to the level of technology used by a child using AAC, even though such differences were found with adults [27]. The attitude measures differed in the reference to 'all children' versus a specific person.

\subsection{Sex Differences}

Results of the current study are also consistent with previous studies using the AATAAC [15, 23, 24, 25], that girls have more positive attitudes than boys. For example, using the AATAAC, Beck, Fritz, and colleagues found an effect for the fifth-grade girls $(\mathrm{M}=3.97)$ compared to the fifth-grade boys $(\mathrm{M}=$ 3.76) [20]. These results are similar to those of the current study $(\mathrm{M}=3.81,3.72$ [girls]; $\mathrm{M}=3.45,3.27$ [boys]). The effect of sex on attitudes is well documented [11]. 


\subsection{Impact of Experience with Disabilities}

An additionally well-documented effect is that individuals with experience with disabilities have more positive attitudes than individuals without experience. For example, Beck, Kingsbury, and colleagues [2] found that mean AATAAC scores for students with experience with disabilities $(\mathrm{M}=3.92)$ were significantly higher than those students without experience with disabilities $(\mathrm{M}=3.63)$. These results are similar to those of the current study $(\mathrm{M}=3.93,3.82$ [experience]; $\mathrm{M}=3.45,3.32$ [no experience]).

\subsection{The Effect of Time}

The effect of time, regardless of group, was unexpected given the reported test-retest reliability of the AATAAC $(p=.01$ and $r=.87)$. This result suggests a possible influence of pre-testing on attitudes. The act of taking the same measurement multiple times may have had an impact on the outcome. In other words, after taking the assessment the first time, students may have had time to reflect on their responses and change their opinion and feelings the second time. Also, the presence of the researcher might have resulted in students misrepresenting their attitudes to be higher than they were during the first visit; students might have altered their responses to be more socially appealing. The second visit might have resulted in a more accurate attitude reports once students were accustomed to the presence of the researcher. Very few studies involving attitudes in the AAC literature measure baseline attitudes prior to the intervention. For this reason, there is little information on how attitudes change from baseline to intervention, and how they change as a result of taking the same measurement repeatedly. Previous studies utilizing the AATAAC were studies with post-test measurements only. McCarthy and colleagues [13] used a Solomon Four Group Design [28] to study pre-professionals in business and their attitudes toward an individual using AAC. The authors found a potentially reactive effect for pretesting on the affective subscale of the instrument used suggesting that emotional reactions could potentially drive pre-post differences in attitudes.

\subsection{Qualitative Results}

There were several positive findings that emerged from the qualitative analysis indicating that even a brief amount of information could help individuals to consider new and potential for increased participation with an individual using AAC.

Benefits. The majority of participants discussed positive benefits of being friends with someone like Kathrin, benefits such as having a friend, having fun, and qualities of Kathrin they would look for in a friend. A large portion of participants also appeared to frame the relationship as a learning experience: to learn about disabilities. These participants saw a benefit of having the opportunity to learn about someone who is different from themselves, and as a result they would have the opportunity to learn from Kathrin about her disability and AAC. Caution is warranted though since some participants described a friendship where they took on the role of helper rather than peer.

Challenges. The majority of participants discussed communication as a challenge with being friends with someone like Kathrin. In the narrative, Kathrin stated that her friends and family (people who know her well) were able to communicate with her easily. Based on their comments, participants in the study appeared to focus more on the challenge of communicating with Kathrin initially. The positive side of these comments is that partner instruction in interaction strategies is something for which there is a good instructional base [29]. An intervention to change attitudes that also contains partner communication instruction could be extremely valuable. It was interesting that two participants mentioned sign language and deafness. An explanation for this finding could be that participants did not get sufficient information to consider that there could be some individuals who can hear, but cannot speak. Some participants in the current study may have, in effect, resorted to a preconceived notion about people who are unable to talk or hear, rather than considering a new category. Comments about deafness and sign language suggest that more information over a longer period is necessary to allow participants to add a new category of 'people who can hear but cannot talk' to their cognitive classification system.

It was interesting that two participants mentioned sign language and deafness. An explanation for this finding could be that participants did not get sufficient information to consider that there could be 
some individuals who can hear, but cannot speak. Some participants in the current study may have, in effect, resorted to a preconceived notion about people who are unable to talk or hear, rather than considering a new category. Comments about deafness and sign language suggest that more information over a longer period of time is necessary to allow participants to add a new category of "people who can hear but cannot talk" to their cognitive classification system.

Future Perceptions. The majority of participants saw someone like Kathrin having a future career as a teacher, or someone who helps others. Participants reported this was "based on her experiences." Other occupations were also mentioned, which suggested that the second largest percentage of participants could think beyond her disability. However, participants also commented on her physical limitations, which they saw as a hindrance to her future abilities. Based on comments about her physical status, it is difficult to determine if they thought she had fewer opportunities in the future because of her physical limitations or because of her speech limitations. It is also possible that participants saw her as a teacher or helping others because school-aged participants are exposed to education and possibly see females as teachers or motherly figures; therefore, Kathrin would fit into one of those roles, regardless of her disability.

\subsection{Limitations}

As noted previously, since the AATAAC only measures attitudes toward all children who use AAC, is not possible to know whether attitudes toward Kathrin specifically were impacted as the result of the intervention. Individuals may have differential attitudes toward different groups of individuals with disability [1]. It is important to consider whether the goal of interventions to change attitudes has to do with those aimed at increasing the participation of a particular student or set of students in a school versus all individuals with disabilities that someone might ever encounter.

Another limitation was the absence of behavioral and maintenance measures. The relationship between attitudes and behavior is complex [1]. It is not possible to assume self-reported attitudes will match future behavior. Although the AATAAC contains "behaviorally" oriented items, factor analysis has revealed the behavioral responses on the AATAAC are heavily influenced by affective responses [20]. McCarthy and colleagues used a scale of behavioral intentions to examine potential future employer behavior [13]. A similar measure of intentions could potentially help to supplement an understanding of attitudes and future behavior. In terms of maintenance, it is important to know whether or not changes in attitudes are lasting. Although it is possible the post hoc intervention brought attitude scores back up to baseline levels, the choice to include both groups in the post hoc intervention precludes an understanding of the role of variation related to time elapsed after the second session.

\subsection{Directions for Future Research}

Future research in this area should examine the effect of providing accurate information about AAC and individuals who use AAC in addition to demonstrations and interactions with several different types of AAC devices. The information should clearly describe the abilities of someone who uses AAC. Specifically, explanations of AAC and the speech and language abilities of the individual in the narrative should be described thoroughly, to prevent misunderstandings about expressive and receptive language and hearing abilities.

The use of a first-person narrative can be utilized in future research, but it could be important to consider a selection of multiple narratives to represent different people requiring AAC as well as persuasive text. In addition to being informative, narratives could contain passages of persuasion to challenge negative beliefs, which will influence the targeted individual to think critically about the information and integrate it into their own personal belief system. Comprehension checks after the narratives are read could be important in establishing that each child had read, considered and not misunderstood any aspects of the readings. At the time of pre-test and post-test a comprehension check can be administered to ensure that each child understands the concept of AAC and individuals who use AAC. It may even be beneficial for the researcher to encourage a discussion with the students after reading the story, by supplying questions about topics that may potentially be confusing. Interventions that last several sessions, rather than one brief intervention period, should also be examined for an effect on attitudes. Introducing the topic and re-visiting the material over a period of time will allow children 
to be exposed continually to a variety of individuals with communication disorders and different types of AAC systems, thereby allowing them to continually reflect and evaluate the material. Attitudes are not changed easily and influencing attitudes gradually may result in better long-term benefits for the participants. The multiple sessions should include the narratives, multi-media components such as videos, simulations, hands-on components, and other activities available through the Internet, and opportunities for reflection (journal writing, answering questions, and other activities). Attitudes and behaviors can be tracked over time in such interventions. Directions for future research include developing more systematic, extended interventions focused on qualitative as well as quantitative investigations designed to capture children's experiences with AAC and individuals who use AAC. Understanding attitudes through qualitative means will allow researchers to understand what misunderstandings children have and provide a stronger foundation for developing beneficial intervention protocols targeting attitude change in preadolescent students without disabilities.

\section{References}

1. Siperstein, G. N., Norins, J., \& Mohler, A. (2007). Social acceptance and attitude change: Fifty years of research. In J. W. Jacobson, J. A. Mulick, \& J. Rojahn (Eds.), Handbook of intellectual and developmental disabilities (pp. 133-154). New York: Springer.

2. Beck, A., Kingsbury, K., Neff, A., \& Dennis, M. (2000). Influence of length of augmented message on children's attitudes toward peers who use augmentative and alternative communication. Augmentative and Alternative Communication, 16, 239-249.

3. Williamson, P., McLeskey, J., Hoppey D., Rentz T. (2006). Educating students with mental retardation in general education classrooms. Exceptional Children, 72(3), 347-361.

4. Beck (2009) Insert citation

5. Moore, D. \& Nettelbeck, T. (2013). Effects of a short-term disability awareness training on attitudes of adolescent schoolboys toward persons with a disability. Journal of Intellectual and Developmental Disability, (38)3, 223-231.

6. Macmillan, M., Tarrant, M., Abraham, C., \& Morris, C. (2014). The association between children's contact with people with disabilities and their attitudes towards disability: a systematic review. Developmental Medicine \& Child Neurology, 56, 529-546.

7. Pettigrew, T. F., \& Tropp, L. R. (2006). A meta-analytic test of intergroup contact theory. Journal of Personality and Social Psychology, 90, 751-783.

8. Cameron \& Rutland (2008). An integrative approach to changing children's intergroup attitudes. In Intergroup attitudes and relations in childhood through adulthood. (pp. 191-203). New York, NY, US: Oxford University

9. Mike Clarke, Helen McConachie, Katie Price and Pam Wood. (2001) Views of young people using augmentative and alternative communication systems. International Journal of Language and Communication Disorders (36)1, 107-115.

10.De Boer, A., Pijl, S.J., \& Minnaert, A. (2012). Students' attitudes towards peers with disabilities: a review of the literature. International Journal of Disability, Development and Education, (59)4, 379-392.

11.McCarthy, J., \& Light, J. (2005). Attitudes toward individuals who use augmentative and alternative communication: Research review. Augmentative and Alternative Communication, 21, 41-55.

12.Beck, A., \& Fritz-Verticchio, H. (2003). The influence of information and role-playing experiences on children's attitudes toward peers who use AAC. American Journal of Speech-Language Pathology, 12, 51-60.

13.McCarthy, J., W., Donofrio-Horowitz, L. M., \& Smucker, L. M. D. (2010). The effects of reading personal narratives written by an individual who uses AAC on the attitudes of pre-professionals in business. Augmentative and Alternative Communication, 26(2), 61-74.

14.Dal Cin, S., Zanna, M., \& Fong, G. (2004). Narrative persuasion and overcoming resistance. In E. Knowles \& J. Linn (Eds.), Resistance and persuasion (pp. 175-191). Mahwah, NJ: Lawrence Erlbaum Associates.

15.Wright, S. C., Aron, A., McLaughlin-Volpe, T., \& Ropp, S. A. (1997). The extended contact effect: Knowledge of cross-group friendships and prejudice. Journal of Personality and Social Psychology, 73(1), 73-90.

16.Cameron, L. \& Rutland, A. (2006) Extended contact through story reading in school: Reducing children's prejudice towards the disabled. Journal of Social Issues, 62, $469-488$. 
17.Cameron, L., Rutland, A., Turner, R., Blake, B., Holman-Nicolas, R., \& Powell, C. (2011). Changing attitudes with a little imagination': Imagined contact effects on young children's intergroup bias. Anales de Psicologia, $27(3), 708-717$.

18.Lee, T., \& Rodda, M. (1994). Modification of attitudes toward people with disabilities. Canadian Journal of Rehabilitation, 7(4), 229-238.

19.Shaver, J., Curtis, C., Jesunathada, J., \& Strong, C. (1989). The modification of attitudes toward persons with disabilities: Is there a best way? International Journal of Special Education, 4, 33-57.

20.Beck, A., Fritz, H., Keller, A., \& Dennis, M. (2000). Attitudes of school-aged children toward their peers who use augmentative and alternative communication. Augmentative and Alternative Communication, 16, 13-26.

21.Lemler, K., \& Gemmel, S. (1997). Kathrin Talks with her Eyes. Kevelaer: Verlag Butzon and Bercker.

22.McNulty, F. (2005). If you decide to go to the moon. New York: Scholastic Press.

23.Vaughn, S., Schumm, J. S., \& Sinagub, J. (1996). Focus group interviews in education and psychology. Thousand Oaks, CA: Sage Publications.

24.Cameron, L., Rutland, A. \& Brown, R. (2007) Promoting children's positive intergroup attitudes towards stigmatized groups: Extended contact and multiple classification skills training. International Journal of Behavioral Development, 31, 454 - 466. communication.

25.Blockberger, S., Armstrong, R., O'Connor, A., \& Freeman, R. (1993). Children's attitudes toward a nonspeaking child using various augmentative and alternative communication techniques. Augmentative and Alternative Communication, 9, 243-250.

26.Gorenflo, C., \& Gorenflo, D. (1991). The effects of information and augmentative communication technique on attitudes toward nonspeaking individuals. Journal of Speech and Hearing Research, 34, 19-26.

27.Beck, A.R. (2009). Attitudes toward children and teens who use AAC: Have they changed in 20 years? Perspectives on Augmentative and Alternative Communication, 18, 96-102.

28.Solomon, R. (1968). A control group design for experimental students of the developmental processes. Psychological Bulletin, 70(3), 145-150.

29.Kent-Walsh, J., \& McNaughton, D. (2005). Communication partner instruction in AAC: present practices and future directions. Augmentative and Alternative Communication, 21(3), 195-204. 